DOI: 10.20472/IAC.2018.042.012

GIRAY GERIM

Eötvös Loránd University, Hungary

\title{
BETWEEN A COMBINATIVE PERSPECTIVE AND SELF-CONTAINED PRACTICE: A CRITICAL REVIEW OF ETHNOMETHODOLOGY
}

\begin{abstract}
:
Ethnomethodology (EM) brought a new vision to social studies by putting the construction of social reality through everyday life and practices of the members of society at the center and questioning what is taken granted conventionally in social research. However, it is doubtful if EM possesses a systematic and comprehensive approach to explain the social world extensively as a fully-fledged practice or framework of analysis. Moreover, it shows a very fragmented structure regarding the studies in the field. Based on these aspects, this article problematizes the extent of EM's contribution to social analysis. The argument of this work is that it is not suitable to be considered a separate framework of social analysis due to the drawbacks mentioned; nevertheless it has a significant potential to contribute to the examination of social reality if it is integrated into the theoretical and/or methodological frameworks of social analyses as a perspective. The argument is defended through critical reading of the primary and secondary sources which deals with EM theoretically and also discussing some studies which can be regarded as its applications in social research.
\end{abstract}

\section{Keywords:}

social analysis, ethnomethodology, ethnomethodological perspective, ethnomethodological approaches

JEL Classification: Z00, Y90, Y80 


\section{Introduction}

Garfinkel's Studies in Ethnomethodology (1967) can be regarded as the foundational text of ethnomethodological studies. To figure out what the term ethnomethodology (EM) means, we should pay attention to how Garfinkel addresses the term in his book:

I use the term "ethnomethodology" to refer to the investigation of the rational properties of indexical expressions and other practical actions as contingent ongoing accomplishments of organized artful practices of everyday life. (p. 11)

Just starting from this reference, we can see that EM shifts the focus from the big picture to the parts which are usually taken for granted.

It is quite likely to say that EM actually developed from the criticism of conventional American sociology, which was under the dominance of structural functionalism. Ethnomethodologists claimed that taken-for-granted assumptions of conventional sociologists undermined sociological analysis. According to them, especially the cognitive consensus among these sociologists, which assumes that actors see the social world in the same way, weakened reliability of conventional sociology (Law \& Lodge, 1978, p. 373).

A key aspect of ethnomethodology is that it puts the everyday life and practices to the center. According to Heritage (1984, p. 4), the original motivation behind EM was "to capture a range of phenomena associated with the use of mundane knowledge and reasoning procedures by ordinary members of society."

In addition to the above, ethnomethodological studies trace the influence of people's standpoints on the way they think and act. Therefore, ethnomethodologists scrutinize "their physical and social circumstances, their habits, the habits of those around them, their background knowledge, and their practical motives" (Handel, 1982, p. 4). All of these have effects on how people make sense of their environment and respond to it.

One of the main claims of ethnomethodology is that every account is reflexive. Social settings are made up of accounts, while accounts establish what is accountable in a social setting. It means that accounts define the reality, but they are also that reality. In other words, accounts are the medium of definition and accountability, and they create the defined, accountable world as well (Handel, 1982, p. 39).

However, the constant construction of reality through accounts limits the opportunity of EM to carry out large-scale researches. Livingstone (2008) asserts that EM's premise to examine the self-organizing, local ways of doing an activity to grasp its logic coming from practical purposes paves the way for small-scale studies. It possesses the reason to 
analyze the social order being produced while avoiding a totalizing conception; but the outcome becomes a fragmented collection of studies, which he called "a cabinet of reasoning" (p. 844).

Parallel to Livingstone to a certain extent, I argue that EM does not have the competence to be seen as an independent practice which provides the framework for a comprehensive social analysis, although it has brought a revolutionary new insight to social analysis. Thus, it can be considered as a combinative perspective in social research instead of being used as a complete analysis structure of research. In order to examine EM's pros and cons in terms of social analysis and expose what it means for social research; an extensive understanding of this approach's framework, epistemological background and reference points is essential. In this study, I will attempt to support and elaborate my argument through such an analysis.

\section{Epistemological Ground, Premises and Key Concepts of Ethnomethodology}

It is accepted that ethnomethodology is based on an alternate reading of Durkheim's famous aphorism, 'The objective reality of social facts is sociology's fundamental principle." Although this aphorism is understood mostly as a principle which means that sociology has to be built on objective reality of social facts, Garfinkel interprets it differently. By considering that objective reality of social facts is the accomplishment of the members of society, he focuses on its processes (Garfinkel \& Rawls, 2002, pp. 117118). This understanding is fundamental for ethnomethodology since such an objective reality can be observed as an ongoing, locally produced, naturally organized and accountable achievement of any society. At this point, phenomenology provides a ground for EM to analyze and elucidate the construction and maintenance processes of objective reality in social settings. While bringing an explanation of how members experience and construct the world as real, phenomenology doesn't deny the reality of the objects in the outer world. It just points at "the acts of perception that refer to one another and to some connected whole" (Maynard \& Clayman, 1991, p. 389). Schütz, in particular, helped Garfinkel to break away from Parson's approach of the social world based on cultural dopes and to find a new way of doing sociology resting on everyday practices and grounding on phenomenological assumptions (Ruggerone, 2013, p. 187). However, it should be noted that Schütz focused on the a priori conditions of intersubjectivity, while EM emphasized "the immediate accountability of everyday practices" (p. 195).

The commonsense attitude is another primary concept of the epistemological frame of EM. It is borrowed from Schütz and has a remarkable influence on the development of ethnomethodology. In this attitude, a practical motivation is essential to address the world and people always seek to reduce ambiguity and clarify the meanings. Knowledge may fail and anybody may face confusion or ambiguity; but this situation only means that there 
is lacking information or knowledge and it can be overcome by investigation. In this way, we can stabilize the world to act in it and achieve our goals (Handel, 1982, p. 46).

The use of language is a main feature to observe the commonsense attitude and practical reasoning in everyday life on which EM focuses. But EM's focus point is not directly the structure or rules of the language. Before handling indexicality which is one of the key concepts in EM, it has to be touched on shortly. Cicourel (1974) stresses the distinction in the handling of the problem of meaning in linguistic and ethnomethodological approaches. The former focuses on the logical relationships and rules to describe the connection between sound patterns and the objects, events or experiences to which they refer. Thus, it puts an emphasis on syntactic rules for semantic analysis while minimizing the significance of interactional context-sensitive aspects. However, EM is concerned with the process through which interactional settings are constructed. That is why; it prescribes the necessity of interpretive work to recognize the existing abstract rules which can fit a specific occasion (Cicourel, 1974, p. 99-100).

\section{Indexicality}

Since supplementary information is conveyed non-verbally when they are used, indexical expressions usually do not cause misunderstandings in everyday life. When somebody says "it is raining" in a daily communication, the place and the time are known; so the ambiguity is reduced. However, this sentence may retain its ambiguity in various ways. For instance, its meaning differs on a picnic day, at the end of a drought, or at the risk of a river flood (Handel, 1982, p. 40-41). Since indexical expressions have been regarded as a spot or dirt on "the white wall of the language," philosophers and scientists have debated on how to remove the blemish and struggled to scrub the wall clean. Nevertheless, Garfinkel (and Sacks as well) proposed to examine that spot closely and to describe its characteristic (Handel, 1982, p. 42). That was a new position in social sciences.

Nevertheless, it would be wrong to claim that indexicality is understood by ethnomethodologists in the same way. Barnes and Law (1976, p. 226) point out that current EM is divided on the distribution of indexicality. While some argue that it is a universal phenomenon, others claim that literal or non-indexical description is possible. But they claim that everything is indexical, even in the sciences which is considered to have certainty such as mathematics. They present Lakatos' account of the history of Euler's Theorem to illustrate the essential indexicality of mathematics. It exhibits a constant revision of the meaning of terms or an important exercise in repairing indexicality and it is an endless struggle. Thus, they end up with the conclusion that the search for the literal expression and meaning is always fruitless, even in mathematics ( $p$. 
234). In spite of various attitudes with respect to indexicality, the emphasis on it has contributed to social analysis beyond the mentioned discussions.

\section{Documentary Method of Interpretation}

To envisage the practical reasoning which is assumed as the basis of social actions in everyday life, Mannheim is a key figure. According to Mannheim (1964), documentary knowledge is the knowledge of the patterns which underlie behavior. For instance, by looking at the examples of an art movement, one can gain an understanding of that art movement and figure out what it is about. Once the pattern is obtained, each art piece is situated in its place in the pattern and interpreted according to that. It can easily be seen that the process also shows a reciprocal feature (Handel, 1982, p. 47).

Documentary method of interpretation is actually a way of understanding the part from the whole and the whole from the part. It alludes to an ultimate circle indeed. The same process is operative when we recognize or interpret a person, a book or a cultural movement as well (Liberman, 2013, p. 240). Observing the coffee cupping of some professional tasters, Liberman illustrates the documentary method of interpretation. The tasters solicit each other's participation into cupping, because they learn new ways of describing tastes they may have developed, and they recognize that there is always something more to discover and describe in flavor. All they do in cupping is a document of how cupping is and vice versa (p. 265). Another significant point in the same case is what one of coffee producer told the tasters while marking the value of the cupping: "We want to learn more about what we're doing" (Liberman, 2013, p. 266) In my view, this statement elucidates very well what ethnomethodology means by documentary method.

\section{The Structure-Agent Dichotomy}

The structure-agent dichotomy occupies a large place within EM just as it does in sociology in general. As one of the important figures in EM, Sharrock (1989) defines that one of the crucial issues among the sociologist is the disagreement on the ratio of the contributions made by individual and social structure in determining the outcomes. In other words, to what extent individuals are free or restricted (or controlled) by factors which are beyond their choices. He observes that EM is recruited into this agreement and placed into the camp which features agency against structure (Sharrock, 1989, p. 669). But of course this is a rough classification and cannot tell much about the position of EM in sociology. According to Sharrock, there can be identified two main standings about the social facts; such as that they are in the outer world as external things, or they are 'in the minds' of the individuals. However, as an ethomethodologist, he argues that social facts are actually found entirely "within (socially organized) practices by which they are assembled" (Sharrock, 1989, 673). 
Bruce and Wallis (1983, p. 65) lay stress on another dimension of structure-agent relations in EM. They put forward that EM, although it claims that it is quite different from conventional sociology, does not consider the speech of the actors as something which reflects their motives. Because the actors are driven by "some variant of a desire to appear rational, decent, sensible and honest and a desire to win some interactional advantage." In other words, EM allows motives to precede speech acts which render them accountable; but it is unwilling to allow motives to precede other types of acts and still make use of speech to make inferences about motives. According to Bruce and Wallis, this approach is just arbitrary. In addition, ethnomethodologists oppose conventional sociology's motive attribution to social actions, yet they admit that they are forced into motive attribution in certain occasions. Then, this aspect is just about the plausibility of attributions and EM's criticism of conventional sociology with regard to this aspect would be futile in terms of a conventional sociologist who is cautious about the usage of motive attributions (Bruce \& Wallis, 1985, 468).

It is claimed that structuralist approaches dismiss the subjective presence of actor in favor of common cognitive, linguistic and symbolic mechanisms in societies in order to interpret and convey the meaning (Julles-Rossette, 1986, p. 405). In contrast to them, quoting from Garfinkel (1967, p. 30), Julles-Rossette (1986, p. 406) states that common understanding is an operation which is achieved through the interpretive work of language (both the said and the unsaid) in social context, rather than being a common intersection of overlapping sets as in structuralist approaches. In other words, EM views social settings within a subjectivity brought by agents.

\section{Ethnomethodological Indifference}

Ethnomethodological indifference is a policy which is usually misunderstood by thinking at it refers to an indifference to aspects of society such as issues of social order and social structure. Nevertheless, it refers to indifference over the requirements and necessities of formal analytic inquiry and argument (Garfinkel \& Rawls, 2002, p. 170171). Although it does not defend the abandonment of established studies or methods, deciding on the direction of the methodology in and as the study according to practical observability and practical objectivity is what it demands. To some extent, it is similar to the construction of social reality through accounts, in terms of social research activity.

EM does not prepare a prescribed method or standard procedures for the practices it examines; nor does it prepare any remedy for them since it does not ideally define how practices are. What matters to EM is how social accounts are formed during its processes, just free from theoretical assumptions; yet, it is criticized about ignoring some sociological concerns such as authority, power and oppression (de Montigny, 2017, p. 356). However, it can also be argued that EM gives us the opportunity to see these 
concerns in their true contexts and in interaction, rather than definitions or steerings of theories or methodologies.

\section{Ethnomethodological Approach(es) to Social Settings}

When it emerged out as a new perspective, there were struggles to reconcile it with the existing strong approaches. As an early example, Denzin (1969) put an emphasis on the parallel lines between symbolic interactionism and EM. He claims that although placing unit of analysis within the individual and interaction separates interactionism and EM from each other, they share a lot to enable a synthesis. To exemplify, socialization is a ubiquitous and never-ending process of interactions in both (p. 931). As another example, both of them direct their scientific interests to the scientific process itself (p. 933). Departing from these kinds of common parts in their standings, Denzin points out in his study that such reconciliation would give fruitful results for the future sociological efforts. Some sociologists, however, do not regard this kind of struggles useful. For instance, according to Atkinson (1988, p. 461), reconciliation between EM and symbolic interactionism is an example of fruitless struggles since they are "mutually exclusive." Therefore, attempts to establish a common ground for them frequently falter. Yet, as long as such syntheses and reconciliations are explicated well in terms of epistemological borders, in my view, EM possesses the potential to enrich any research frame successfully. It may be conceived as just focusing different dimensions of social settings for a comprehensive framework of analysis.

My argument can be illustrated by the contribution of EM to various fields of social world. EM has given an alternative insight to examine culture and its outcomes in action. Hester \& Eglin's (1997) study is a very good example of it. They focus on related membership categories such as teacher-pupil-psychologist, doctor-patient, boyfriend-girlfriend, sociologist-society-individual etc. and try to shed light on their various dimensions. They state the two main aims of the study as:

- To demonstrate the internality of culture in action; exhibiting the incarnation of social structure in agency.

- To show that ethnomethodological inquiry can offer a new point of view on conventional sociological problems by respecifying sociology's conventional foundations and practices (p. 154).

They do not take classifications or distinctions for granted but rather address the structural; institutionalized phenomena (Hester \& Eglin, 1997, p. 154-155). Instead of beginning with "existing" structures, they give the scene to the accounts which construct those "granted" structures. In my view, EM's remarkable role in social analysis can be 
realized through such studies which create healthier groundwork in analyzing social settings.

The groundwork I mention comes by the critical perspective of EM over the former approaches. Gleeson and Erben (1976, p. 479) give an example of a morning assembly in school to explain the distinction between symbolic interactionist and ethnomethodological approaches. According to the first, that assembly is symbolically important because it revivifies actors' integration and sense of solidarity; it binds them together by singing, praying listening etc. and it renders control over them easier. Yet, in the same case, a standard ethnomethodological approach asks who will decide what is symbolically important and how will we ascertain that all members of that assembly give the same meaning to their attendance with one another and with the researcher.

However, also according to them, since EM is concerned with what has been left out of other accounts; it lacks "an adequate content for the dynamic understanding and interpretation of social occurences," and that prevents EM from providing complete elucidation of how actors act in certain situations; because it does not ask why the situation is there as a social fact (Gleeson \& Erben, 1976, p. 480). They argue that ethnomethodologists produced a new variant of existing empiricism although EM has emerged from dissatisfaction with traditional sociology. Thus, by such a stress on "doing," they neglected the structures, their consciousness and goals which is given them as a result of those doings. By concentrating on the production of meaning and communication, they miss causality, particularly with regard to power and legitimization (p. 480).

In spite of the new vision EM has brought to social analysis, it would be hard to say ethnomethodologist always reach accurate outcomes through their perspectives. Going through an experiment in the study of Garfinkel (1963), Pleasants (1998, p. 19-20) criticizes one of the premises of EM. In the experiment, each subject was asked to formulate ten questions, and they were told that an experimenter-counselor would evaluate their questions and would answer with just "yes" or "no." However, the yes and no answers were just random. The striking finding of the experiment was that the subjects interpreted the counselor's responses as reasonable and useful advice. Moving from this point, Garfinkel argued that individual subjects were not cultural dopes as they had been presented in classical social theory. The individuals' actions have a constitutive structure and through interpretation, they reach the social reality since this process has a reflective character. Nevertheless, according to Pleasants (1998), the interpretation in the experiment is not reflective. Because, to have such a claim, there has to be an attempt to discover the meaning, such as the meaning of a poem, and similarly, the meanings in the strange practices in distant cultures for an anthropologist and so forth. In these cases, the interpretive work is highly reflective; however, in such experiments, the subjects try to 
normalize the events and make them fit into their conventional and customary way of being. Therefore, these are difficult to consider as the examples of reflective accomplishment and Garfinkel's premise about the acts of an individual is not accurate (p. 25). Pleasants defends that individuals are neither cultural (and/or judgmental) dopes, nor essentially reflexive, interpretive actors. They should rather be seen between these approaches and in our evaluation, we should take into account "at which times, in which places, doing which kind of activities, which kind of people are behaving "reflexively', 'dopily', or some combination thereof" (p. 30).

Widely drawing upon Garfinkel's arguments, Rawls attempts to delineate how "social order" is achieved. She proposes that it can be most fruitfully understood as a composition of face-to-face interaction and rule-governed nature of institutions (Rawls, 1989, p. 147). According to Rawls, self, meaning and practical action are products of mutual interactional commitment and this commitment is based on reciprocity of perspectives among participants in an interaction. Institutional values (or principles of organization) are brought out from this commitment. Individual's commitment to the achievement of such a sociality is the ground where self, meaning and practical action emerges; so does social order (Rawls, 1989, p. 166).

The dimensions upon which have been touched present different accounts of how EM views social settings. As the last point, it should be noted that ethnomethodological approaches may also function to clarify elusive social terms and concepts. As an example, Zaunbrecher (2018) deals with "spontaneity" and considers it as an important, nevertheless poorly-analyzed term in social theory and argues that an ethnomethodological perspective can help us to expound it. This is because EM evaluates it as a contextually-emergent social practice, contrary to the term's conceptually-slippery realist accounts.

\section{Main Critical Reflections on Ethnomethodology}

Lynch (1999) asserts that ethnomethodologists have been reticent in relation to their theoretical roots and methodological tenets; because EM's research programs were not successful in creating a practice. It is partly because of the fact that EM required an engagement with other fully-fledged practices. Yet, what EM could take from and contribute to them was ambiguous. I partly agree with Lynch's standpoint. In my view, EM has contributed an unconventional and enriching perspective to social analysis; however, it does not offer an independent structure or practice for social analysis. In order to reveal where it stands in relation to sociology or in the broader scope of social science, I will attempt to address EM in terms of theory and methodology, although I do not claim that there are strict borders between these in EM. 


\section{In terms of Theoretical Framework}

As a consequence of the concept of indifference discussed previously, there is no comprehensive and bordered theoretical ground which belongs to the approach directly, if we disregard the borrowed features of various philosophical concepts and dealings to justify the framework of social analyses conducted by the approach. Rogers (1984, p. 166-167) states similarly that while EM in general, and Garfinkel's works in particular, are replete with references to figures such as Husserl, Schütz and Gurwitsch; the discipline does not possess a consistent relationship even with phenomenology. For instance, ethnomethodological studies show no aspiration to follow what is new in phenomenology and to adopt them into EM. This inconsistency in spite of its eclectic intellectual basis is claimed to make understanding EM as a sociological development more difficult.

In order to comprehend the position of EM according to sociology and, of course, in the larger spectrum of social sciences, how ethnomethodological approaches view "theory" offers a good indicator. Francis \& Hester (2004, p. 208) state that in sociology, description is secondary to and independent on theory. Thus, according to the main assumption in sociology, sociologists need theory as a guide or set of criteria in order to overcome the complexity and vastness of social reality and to sort out the social phenomena. Otherwise, social life cannot be understood systematic, sociologically adequate way. In contrast with this conventional way of thinking, EM insists that social life or its investigations do not require any theory and such an assumption derives from a notion that sociology is looking for "some overall and all-embracing account of social life" (p. 209). Nevertheless, they also state that social activities do not mean anything else from what is going on in them, nor do they refer to some other activities which are responsible for the ones going on here (p. 207). However, through such expressions, EM is understood as a description of what is happening "there," rather than an analysis.

Conventional sociologists have had two main arguments against EM. As the first, since it has no way of dealing with social structure, EM is not capable of addressing macrosociological issues. Secondly, (mostly from a Marxist perspective) it is argued that EM is incapable of conceptualizing power and domination since it is not interested in anything other than the interpersonal level and sense (Law \& Lodge, 1978, p. 373).

The perspective of EM does not pay much attention to the socio-historical background and generalizations for its analyses; that is to say, institutional facts are relevant only as much as they shape part of the member's situated point of view. There is no interest in describing institutional realities independently; that would be remarkable only in terms of the perception of an individual (Francis \& Hester, 2004, p. 203). However, they do not accept EM's being identified with the agency side of the agency-structure dichotomy since they posit that EM focuses on social activities which are produced and carried on 
by the ones who are engaged in it. Hence, it struggles to find out the practical reasoning in these social activities.

Heritage (1984, p. 1-2) draws attention to the disarrangement of the first ethnomethodological studies, especially Garfinkel's and argued that their diversity in terms of substantive topics, -or lack of a connecting theme- is an important problem for the reader to grasp EM's messages. In addition, although programmatic statements could be come across in these studies, it is hard to find any systematically stated theory in which the studies could be integrated. Nevertheless, as a response to this kind of standings, Maynard and Clayman (1991, p. 386) criticize the views which assess EM as a unitary perspective. In addition to this, they diagnose three characteristic ways to pigeonhole EM in theory textbooks and other secondary sources: as a version of symbolic interaction, as an individual-focused approach and a critique of conventional sociology. By that, they reveal the diverse ways to perceive the perspective(s) of EM.

\section{In Terms of Methodology}

The methodological stance of EM has also been a disputed zone. Smith (1991, p. 7-8) argues that EM is just "a methodological critique focuses on the problem of meaning, not a method." EM has demonstrated that people may not use the rules or abstractions in their acts and decision processes; so its defenders have become unwilling to generalize from research. Nevertheless, the resistance against abstraction and generalization and treatment of each event as a potentially new construction of reality limit research alternatives and impedes the growth of general knowledge. Due to such reasons, Smith considers EM as a politicized ideology which creates restrictions in social research such as the other ongoing quarrels over methodological doctrines.

According to Arminen (2008, p. 188), EM has been torn by radical and scientific impulses from the beginning. Radical EM has been focusing on the "situation itself" without resorting to any external sources outside of it. It denies scientific procedures to avoid itself becoming an interpretative science. But this time, it has stuck to the situations and become interpretative again by that way, in order to make inferences from the situations. However, scientific EM has led to the development of conversation analysis (CA) and Arminen claims that CA handles the mundane world by its use of "vernacular interactional competence and situated knowledge" (p. 189). Discussing the framework of CA and its relations to EM is beyond the limits of this article. In addition, this kind of grand separations and generalizations from the supposed cleavages may not be useful; but to some extent, it touches on a remarkable deficit in EM. It is imprisoning itself into the situations to escape from conventional ways of social sciences, and, in that way, it becomes more dependent on interpretations of the situation. 
Perhaps, the most prominent criticism towards EM comes from Pollner (2012). He argues that there is a Wittgensteinian-like schism between the early and later times of EM which he calls EM Version 1.0 and EM Version 2.0 respectively. The method in the first one was "making familiar strange"; on the other hand, what the second seeks is to make the strange familiar (pp. 10-11). Therefore, the researcher is a troublemaker in the first one, who breaks the usual flow of everyday practices; yet, she/he is an adept practitioner in the second and urged to acquire the skills and competencies relevant to the research. Thus, the stance of ethnomethodologist transforms from a stranger who causes trouble in the host domain to a practitioner who endeavours for "seamless and deep involvement". Pollner also juxtaposes some other differences between the versions in terms of reflexivity and ethnomethodological indifference and puts forth the difficulty of conceptualization of EM as not only methodology but also phenomena.

The criticism of EM towards the established methodologies is remarkable contribution to social analysis. However, the same position causes EM to be considered to have a disorder with respect to its methodological frame. Its stance in favor of construction of methodology through research processes could, at best, be considered a methodological position; yet, it may not be accurate within every social analysis. In addition, the changes in the focus of research and position of researcher render EM even more ambivalent in this context.

\section{Conclusion: What Can Ethnomethodology Contribute to Social Analysis?}

I have attempted to show so far that the stance and approaches of EM stand away from constituting a independent and self-contained practice or framework of social analysis. Similarly, as an early critic of EM, Atkinson (1988) appreciates its major contributions to the sociology of everyday life; however, he thinks that EM should not be defined as a separate enterprise. Furthermore, in his view "claiming a more homogeneous and internally consistent program" would not be the right way for EM since its importance and influence come from its links with the other disciplines and sub-disciplines (p. 462). Quere (2012, p. 324) emphasizes that EM opened new perspectives for the study of social order by showing how social settings are reflexive, in which individuals locally constitute the normative milieu in which their practical actions and reasoning take place. Therefore, he posits that EM should hold the different policies in it and pluralize the approach in order to embrace the different action regimes and comprehensions of accountability (p. 325). I consider his view parallel to what I argue here to some extent. Nevertheless, I maintain that the approaches of EM do not have adequateness to analyze the social world comprehensively by its own since their focus points are very limited on a large scale.

I may give an example to explain my stance. In a country, educated or not, every local member of the related society speaks the same language; most of the time paying no 
attention to the rules and mechanisms of that language. The linguists and philologists in this society put an effort to understand such structures, and by this way, local dialects, vocabularies and jargons as well. However, their points of view in terms of these have certain limits if they do not consider the social backgrounds which constitute them such as immigration, economic conditions, and social stratification in the mentioned country or in its regions. Making analyses just from daily talks could not explain how these jargons, dialects etc. emerged and how they are evolving; or to what they indicate. In other words, they can infer information, but in order to elucidate the social actions comprehensively there, it presents a very limited perspective. Staying only within the framework of EM could just lead us to the same problem, to a restricted framework in the analysis of social settings. To illustrate my argument, I refer to Garfinkel's own words:

$E M$ is not in the business of interpreting signs. It is not an interpretive enterprise. Enacted local practices are not texts which symbolize "meanings" or events. They are in detail identical with themselves, and not representative of something else. The witnessably recurrent details of ordinary every- day practices constitute their own reality. They are studied in their unmediated details and not as signed enterprises. (Garfinkel, 1996, p. 8)

As can be seen, according to Garfinkel, events are just analyzed within their confines in EM; they cannot be used in larger interpretive frames. Because they just form their own reality as he remarks.

Could it, however, be a framework for sociology or social sciences to analyze social actions, social settings or social world? As I conclude from the discussion in this paper, it cannot. EM has brought a revolutionary vision and added new perspectives to social analysis through its critical position to the granted assumptions and established ground in it, as I also tried to show in this study. Yet, it can serve and help for the improvement of social analysis only by being integrated into researches of which theoretical and methodological frameworks are taken by other disciplines or sub-disciplines, since it cannot offer a comprehensive framework of analysis for social research. Nevertheless, to offer guidelines on how, by which means and to what extent EM could or should be integrated into the studies in sociology and other social sciences are beyond the scope of this study.

\section{References}

Arminen, I. (2008). Scientific and "'Radical" Ethnomethodology: From Incompatible Paradigms to Ethnomethodological Sociology. Philosophy of the Social Sciences, 38(2), 167-191.

Atkinson, P. (1988). Ethnomethodology: A Critical Review. Annual Review of Sociology, 14(1), 441-465.

Barnes, B., \& Law, J. (1976). Whatever Should Be Done with Indexical Expressions? Theory and Society, 3(2), 223-237. 
Bruce, S., \& Wallis, R. (1983). Rescuing Motives. The British Journal of Sociology, 34(1), 61-71.

Bruce, S., \& Wallis, R. (1985). 'Rescuing Motives' Rescued: A Reply to Sharrock and Watson. The British Journal of Sociology, 36(3), 467-470.

Cicourel, A. V. (1974). Cognitive Sociology: Language and Meaning in Social Interaction. The Free Press.

de Montigny, G. (2017). Ethnomethodological Indifference: Just a Passing Phase?. Human Studies, 40(3), 331-364.

Denzin, N. K. (1969). Symbolic Interactionism and Ethnomethodology: A Proposed Synthesis. American Sociological Review, 34(6), 922-934.

Francis, D., \& Hester, S. (2004). An Invitation to Ethnomethodology: Language, Society and Social Interaction. London: Sage Publications.

Garfinkel, H. (1963). A Conception of, and Experiments with, "Trust" as a Condition of Stable Concerted Actions. In O. J. Harvey (Ed.), Motivation and Social Interaction: Cognitive Approaches (pp. 187238). New York: Ronald Press.

Garfinkel, H. (1967). Studies in Ethnomethodology. New Jersey: Prentice-Hall.

Garfinkel, H. (1996). Ethnomethodology's Program. Social Psychology Quarterly, 5-21.

Garfinkel, H. (2002). Ethnomethodology's Program: Working Out Durkheim's Aphorism. (A. W. Rawls, Ed.) Lanham: Rowman \& Littlefield Publishers.

Gidlow, B. (1972). Ethnomethodology: A New Name for Old Practices. The British Journal of Sociology, 23(4), 395-405.

Gleeson, D., \& Erben, M. (1976). Meaning in Context: Notes towards a Critique of Ethnomethodology. The British Journal of Sociology, 27(4), 474-483.

Handel, W. (1982). Ethnomethodology: How People Make Sense. New Jersey: Prentice-Hall.

Heritage, J. (1984). Garfinkel and Ethnomethodology. Cambridge: Polity Press.

Hester, S., \& Eglin, P. (1997). Culture in Action: Studies in Membership Categorization Analysis (No 4). Washington: International Institute for Ethnomethodology and Conversation Analysis \& University Press of America, Inc.

Jules-Rosette, B. (1986). Interpretive Sociology in Comparative Perspective: Paradigms and Prospects. The Canadian Journal of Sociology, 11(4), 401-417.

Law, J., \& Lodge, P. (1978). Structure as Process and Environmental Constraint: A Note on Ethnomethodology. Theory and Society, 5(3), 373-386.

Liberman, K. (2013). More Studies in Ethnomethodology. Albany: State University of New York Press. 
Livingstone, E. (2008). Context and Detail in Studies of the Witnessable Social Order: Puzzles, Maps, Checkers and Geometry. Journal of Pragmatics, 40, 840-862.

Lynch, M. (1999). Silence in Context: Ethnomethodology and Social Theory. Human Studies, 22(2-4), 211233.

Mannheim, K. (1952). Essays on the Sociology of Knowledge. (P. Kecskemeti, Ed.) Oxford University Press.

Maynard, D. W., \& Clayman, S. E. (1991). The Diversity of Ethnomethodology. Annual Review of Sociology, 17, 385-418.

Pleasants, N. (1998). Experimentation in the Social Sciences: Cultural Dope or Reflexive Agent? A Reflexive Critique of Ethnomethodology. Ethnographic Studies, 3, 17-32.

Pollner, M. (2012). The End (s) of Ethnomethodology. The American Sociologist, 43(1), 7-20.

Ruggerone, L. (2013). Science and Life-World: Husserl, Schutz, Garfinkel. Human Studies, 36(2), 179-197.

Quéré, L. (2012). Is There Any Good Reason to Say Goodbye to "Ethnomethodology"? Human Studies, 35(2), 305-325.

Rawls, A. W. (1989). Language, Self, and Social Order: A Reformulation of Goffman and Sacks. Human Studies, 12(1/2), 147-172.

Rogers, M. F. (1984). Everyday Life as Text. Sociological Theory, 2, 165-186.

Sharrock, W. (1987). Ethnomethodology. The British Journal of Sociology, 40(4), 657-677.

Smith, J. (1991). A Methodology for Twenty-First Century Sociology. Social Forces, 70(1), 1-17.

Zaunbrecher, N. J. (2018). Viewing Spontaneity Ethnomethodologically. Human Studies, 41(1), 1-20. 